\title{
How an audit of epidural patients in a community hospital setting resulted in the development of a formal acute pain management service
}

\author{
David H Goldstein MSc MB BcH BAO FRCPC, Elizabeth G VanDenKerkhof BScN MSc DRPH, \\ Rebecca Sherlock MD, Judy Sherlock RN CNCCC, Susan Harper BSCN Med
}

\begin{abstract}
DH Goldstein, EG VanDenKerkhof, R Sherlock, J Sherlock, S Harper.

How an audit of epidural patients in a community hospital setting resulted in the development of a formal acute pain management service.
\end{abstract}

Pain Res Manage 2001;6(1):16-20.

PURPOSE: To describe the results of an audit of patients who received epidural analgesics postoperatively and the subsequent development of a formal acute pain management service in a community hospital.

METHODS: To understand how epidural analgesia was being used to treat postoperative pain at the Peterborough Regional Health Centre, Peterborough, Ontario, a retrospective chart review was performed. Audits were performed on 178 patients who had received epidural analgesia postoperatively from October 1994 to May 1995. Data pertaining to demographics, epidural analgesia, pain scores and side effects were collected.

RESULTS: Sixty-one per cent of patients received bupivacaine/ fentanyl infusions, and 39\% received epidural morphine boluses. More than $60 \%$ of patients reported no pain postoperatively. Patients who received bupivacaine/fentanyl were more likely than those who received epidural morphine to also receive coanalgesia and transitional analgesia. Patients who received epidural morphine were more likely than those who received bupivacaine fentanyl to experience respiratory depression, hypotension and pruritus. Patients were followed by the anesthesiologist who provided the anesthetic. Anesthesiologists practised independently, and formal policies and procedures did not exist.

CONCLUSIONS: As a result of the audit, an acute pain management service was developed. This included a team that did daily rounds and consisted of a nurse clinician and an anesthesiologist who was assigned to the service on a weekly basis. A committee was created, and formalized policies and procedures were estab- lished. Standardized order sheets, data sheets and a computerized database were developed. Reports for administrative and quality improvement purposes were generated monthly. Education programs were developed. Coanalgesia and transitional analgesia are now part of routine care, and epidural catheter placement close to the site of incision is encouraged. A postoperative nausea and vomiting algorithm, and a treatment regimen for pruritus have also been implemented.

Key Words: Acute pain management; Analgesia; Bupivacaine; Database; Epidural; Fentanyl; Morphine; Postoperative pain; Side effects

\section{Comment une enquête menée auprès de patients traités par analgésie péridurale dans un hôpital communautaire a abouti à la mise sur pied d'un service structuré de traitement de la douleur aiguë}

OBJECTIF : Décrire les résultats d'une enquête menée auprès de patients soumis à une analgésie péridurale postopératoire et la mise sur pied subséquente d'un service structuré de traitement de la douleur aiguë dans un hôpital communautaire.

MÉTHODES : Pour comprendre l'utilisation de l'analgésie péridurale pour traiter la douleur postopératoire au Peterborough Regional Health Centre, à Peterborough, en Ontario, nous avons procédé à un examen rétrospectif des dossiers. Une enquête a été menée auprès de 178 patients soumis à une analgésie péridurale postopératoire entre octobre 1994 et mai 1995. Elle a permis la collecte de données démographiques ainsi que de données sur l'analgésie péridurale, l'évaluation de la douleur et les effets secondaires.

voir page suivante 
RÉSULTATS : Soixante et un pour cent des patients ont reçu des perfusions de bupivacaïne ou de fentanyl, tandis que $39 \%$ des patients ont reçu des bolus de morphine par voie péridurale. Plus de $60 \%$ des patients n'ont signalé aucune douleur postopératoire. Les patients traités à la bupivacaïne ou au fentanyl étaient plus susceptibles d'être soumis à une analgésie d'appoint ou de transition. Les patients traités à la morphine par voie péridurale, eux, étaient plus susceptibles de présenter une dépression respiratoire, de l'hypotension ou du prurit. Les patients ont été suivis par les anesthésistes qui avaient prescrit les anesthésiques. Il s'agissait d'anesthésistes indépendants, et aucune directive officielle ne régissait l'application du traitement.

CONCLUSION : L'enquête s'est soldée par la mise sur pied d'un service de traitement de la douleur aiguë; une infirmière clinicienne et un anesthésiste affecté en rotation toutes les semaines au service effectuent les tournées quotidiennes. On a également procédé à la mise sur pied d'un comité, qui s'est chargé de l'élaboration de directives concernant l'application du traitement. Il a aussi conçu des feuilles d'ordonnance normalisées, des fiches techniques et une banque de données informatisée. Des rapports sont produits tous les mois pour faciliter l'administration et améliorer la qualité. Par ailleurs, des programmes éducatifs ont vu le jour. L'administration concomitante ou transitoire d'analgésiques fait maintenant partie des soins courants. On encourage l'insertion d'un cathéter péridural près du siège de l'incision. Il existe maintenant un algorithme pour le traitement des nausées et des vomissements postopératoires et on a mis au point un schéma thérapeutique pour soulager le prurit.
E pidural analgesia has become a common modality for controlling pain postoperatively. One of the advantages it has over conventional analgesics postoperatively is that it provides very effective pain control with fewer side effects (1-3). The use of epidurals relieves the burden on nursing staff and shortens the patient's hospital stay (4). The disadvantage of epidural analgesia is that there must be specially trained physicians to insert the catheter and staff with nursing certification to maintain it (5). Other disadvantages of the epidural are the possibility of late respiratory depression and the slightly increased risk of serious sequelae $(3,4)$.

In 1994/95, epidural analgesia was being used routinely for postoperative pain control at the Peterborough Regional Health Centre (PRHC), Peterborough, Ontario. Anesthesiologists varied in their perioperative care of these patients, which resulted in inconsistent pain control for patients, and confusion for nursing and medical staff. To begin making informed decisions about the effective management of epidural anesthesia postoperatively, a retrospective chart review was performed to gather information on current practice and outcomes. The purpose of this paper is to describe the findings when different analgesic regimens were used in patients who received epidural analgesia postoperatively and to explain how these findings led to the subsequent establishment of the acute pain management service (APMS) at the PRHC.

\section{PATIENTS AND METHODS}

The PRHC, formerly the St Joseph's Health Centre and the Peterborough Civic Hospital, is a regional referral centre that serves a population of approximately 250,000 in a largely rural area northeast of Toronto, Ontario. At the time of this study, the PRHC had a bed capacity of 387 . Surgical services included all major subspecialties, with the exception of neurosurgery and cardiac surgery. Many patients were receiving epidural analgesia postoperatively by the early 1990s.

To elucidate the impact of epidural analgesia on patient care and to assist in developing a data collection tool, a retrospective chart review was performed on all patients $(n=178)$ who had lumbar epidurals inserted for postoperative analgesia between October 1994 and May 1995. Patients were excluded if the epidural was used as the sole anesthetic. Data were collected from the 'epidural pain assessment' sheet that had been devel- oped by the Department of Nursing at the PRHC, from the physicians' progress notes and orders, and from the nurses' notes.

The variables collected were age, sex, surgical procedure performed, duration of epidural, type of epidural analgesic, pain scores postoperatively, administration of additional analgesia (nonsteroidal anti-inflammatories as coanalgesia or narcotics for breakthrough pain), administration of transitional analgesics before discontinuation of the epidural (eg, oral acetaminophen with either oxycodone or codeine) and observed side effects. The potential side effects included nausea and vomiting, sedation, respiratory depression, hypotension, and pruritus. The sedation level of the patient was assessed every $1 \mathrm{~h}$ for $12 \mathrm{~h}$, then every $2 \mathrm{~h}$ using a sedation scale. The registered nurse reported a score of 0 if the patient was not sedated, a score of 1 if the patient was sleeping normally, a score of 2 if the patient responded to verbal stimuli but remained drowsy, and a score of 3 if the patient did not respond to verbal stimuli. For the purposes of this study, the patient was considered sedated if his or her score was 3 . Respiratory rates were assessed every $1 \mathrm{~h}$ for the first $12 \mathrm{~h}$, then every $4 \mathrm{~h}$. Respiratory depression was defined as a respiratory rate that was less than $10 \mathrm{breaths} / \mathrm{min}$. Continuous oxygen saturations were performed but not reported. Blood pressure was monitored every $1 \mathrm{~h}$ for $2 \mathrm{~h}$, then every $2 \mathrm{~h}$. Hypotension was defined as a systolic blood pressure of $20 \%$ below the patient's baseline. Pruritus was assessed every $12 \mathrm{~h}$.

The patient's self-reported pain level at rest was rated on a verbal modification of the Visual Analogue Scale (VAS) between 0 and 10, with 0 being no pain and 10 being the most severe pain (6). The pain scores were reported at $0,6,12,24$, 36 and $48 \mathrm{~h} ; 0 \mathrm{~h}$ was when the patient awoke in the postanesthetic care unit. Data were not collected at the time of initiation of epidural (ie, intraoperatively or postoperatively); therefore, the varying administration times of the initial epidural dose meant that this time would be an inadequate measure of epidural effectiveness if it were considered to be $0 \mathrm{~h}$. Two postoperative periods were selected, $6 \mathrm{~h}$ and $36 \mathrm{~h}$. The pain score reported at $6 \mathrm{~h}$ was thought to be the best measure of pain control in the immediate postoperative period. The VAS score at $36 \mathrm{~h}$ was thought to reflect pain levels in the majority of patients once ambulation had begun. 
TABLE 1

Patient characteristics and Visual Analogue Scale (VAS) pain scores 6 and $36 \mathrm{~h}$ after operation, with cross-tabulation by type of epidural medication

\begin{tabular}{|c|c|c|c|c|}
\hline Characteristic & Total (\%) & $\begin{array}{l}\text { Bupivacaine/ } \\
\text { fentanyl* (\%) }\end{array}$ & $\begin{array}{c}\text { Epidural } \\
\text { morphine } \\
(\%)\end{array}$ & $\mathbf{P}$ \\
\hline Age (years) & $\mathrm{n}=178$ & $n=108$ & $n=70$ & \\
\hline$<65$ & $54(30.3)$ & $40(37.0)$ & $14(20.0)$ & 0.048 \\
\hline $65-74$ & $79(44.4)$ & $42(38.9)$ & 37 (52.9) & \\
\hline$\geq 75$ & $45(25.3)$ & $26(24.1)$ & $19(27.1)$ & \\
\hline Sex & $n=178$ & $n=108$ & $\mathrm{n}=70$ & \\
\hline Male & 88 (49.4) & $48(44.4)$ & $40(57.1)$ & 0.098 \\
\hline Female & 90 (50.6) & $60(55.6)$ & 30 (42.9) & \\
\hline Procedure & $\mathrm{n}=178$ & $n=108$ & $\mathrm{n}=70$ & \\
\hline Orthopedic & $80(44.9)$ & $64(59.3)$ & $16(22.9)$ & 0.001 \\
\hline Vascular & 55 (30.9) & $27(25.0)$ & $28(40.0)$ & \\
\hline Abdominal & $8(4.5)$ & $5(4.6)$ & $3(4.3)$ & \\
\hline Thoracic & 35 (19.7) & $12(11.1)$ & 23 (32.9) & \\
\hline $\begin{array}{l}\text { VAS pain score } \\
\text { after } 6 \mathrm{~h}\end{array}$ & $n=173$ & $n=106$ & $n=67$ & \\
\hline No pain & $104(60.1)$ & $70(66.0)$ & 34 (50.8) & 0.004 \\
\hline $1-3$ & $43(24.9)$ & $24(22.6)$ & $19(28.4)$ & \\
\hline$\geq 4$ & $26(15.0)$ & $12(11.3)$ & 14 (20.9) & \\
\hline $\begin{array}{l}\text { VAS pain score } \\
\text { after } 36 \mathrm{~h}\end{array}$ & $n=141$ & $\mathrm{n}=88$ & $n=53$ & \\
\hline No pain & $99(70.2)$ & 71 (80.7) & $28(52.8)$ & 0.010 \\
\hline $1-3$ & $30(21.3)$ & $14(15.9)$ & $16(30.2)$ & \\
\hline$\geq 4$ & $12(8.5)$ & $3(3.4)$ & $9(17.0)$ & \\
\hline
\end{tabular}

*Bupivacaine $0.1 \%$ with fentanyl $4 \mu \mathrm{g}$

Descriptive statistics were completed for demographic data, VAS scores, coanalgesia or transitional analgesia, and side effects; these statistics included all patients and were crosstabulated by the type of epidural analgesia. Significant differences $(\alpha<0.05)$ between the types of epidural analgesia were calculated using $\chi^{2}$ analysis.

\section{RESULTS}

The sample size of 178 patients who received epidural analgesia postoperatively were classified between 1 and 3 using the American Society of Anesthesiology classification system. One hundred eight patients received bupivacaine/fentanyl (BF) mixture and 70 who received epidural morphine (EM). The BF mixture was administered as a continuous infusion at 6 to 12 $\mathrm{mL} / \mathrm{h}$. One hundred three of the BF patients received $0.1 \%$ bupivacaine with fentanyl $4 \mu \mathrm{g} / \mathrm{mL}$, and the other five patients received bupivacaine $0.12 \%$ with fentanyl $2 \mu \mathrm{g} / \mathrm{mL}$. EM was administered in 3.0 to $4.5 \mathrm{mg}$ boluses (with or without a saline flush) every $8 \mathrm{~h}$ or as requested by the patient. The orders varied among anesthesiologists.

Table 1 shows the patient characteristics of the chart audit. Seventy per cent of the patients were 65 years of age or
TABLE 2

Cross-tabulation of patients receiving additional analgesia and type of epidural medication

\begin{tabular}{lcccc}
\hline Characteristic & Total (\%) & $\begin{array}{c}\text { Bupivacaine/ } \\
\text { fentanyl (\%) }\end{array}$ & $\begin{array}{c}\text { Epidural } \\
\text { morphine (\%) }\end{array}$ & $\mathbf{P}$ \\
\hline Coanalgesia* $^{\prime}$ & $\mathrm{n}=140$ & $\mathrm{n}=85$ & $\mathrm{n}=55$ & \\
$\quad$ No & $49(35.0)$ & $24(28.2)$ & $25(45.5)$ & 0.037 \\
$\quad$ Yes & $91(65.0)$ & $61(71.8)$ & $30(54.5)$ & \\
$\begin{array}{c}\text { Transitional } \\
\text { analgesia }\end{array}$ & $\mathrm{n}=178$ & $\mathrm{n}=108$ & $\mathrm{n}=70$ & \\
$\quad$ No & $147(82.6)$ & $86(79.6)$ & $61(87.1)$ & 0.197 \\
Yes & $31(17.4)$ & $22(20.4)$ & $9(12.9)$ & \\
\hline
\end{tabular}

*The administration of nonsteroidal anti-inflammatories as coanalgesia or narcotics for breakthrough pain; ${ }^{+}$The initiation of oral analgesics before discontinuation of the epidural

older (mean 68.7 years, range 32 to 88 years), with almost equal numbers of males and females. Approximately $45 \%$ of the patients had orthopedic surgery, $30 \%$ had vascular surgery (including abdominal aortic), almost $20 \%$ had thoracic surgery and fewer than 5\% had abdominal surgery. Many of the patients reported a pain score of 0 at each time interval. The mean VAS scores ranged from 0.9 to 2.1 , and the median was always 0 . Table 1 also presents the VAS pain scores at 6 and $36 \mathrm{~h}$ postoperatively. Approximately two-thirds of the patients reported no pain, and over $80 \%$ reported pain scores under 4 . The mean duration of epidural use was $56.9 \mathrm{~h}$ or 2.4 days.

Table 1 presents patient characteristics and pain scores stratified by type of epidural analgesic. Patients who received $\mathrm{BF}$ were more likely to be under 65 years of age than patients who received EM. BF was more likely than EM to be administered to orthopedic patients (59.3\%), while EM was more likely than BF to be administered to vascular $(40.0 \%)$ and thoracic (32.9\%) patients. BF patients were more likely to report no pain than EM patients.

Table 2 presents the results of the cross-tabulation of additional analgesia (coanalgesia and transitional analgesia) and the type of epidural analgesia. When the audit was initially established, data were not collected on coanalgesia; therefore, this information is missing for 38 patients. Over two-thirds of the patients who were audited received coanalgesia, and $17.4 \%$ received transitional analgesia. BF patients were significantly more likely to receive coanalgesia than EM patients. They were also more likely to receive transitional analgesia, but the difference between the two groups was not significant.

Table 3 shows the incidence of side effects for all patients and is stratified by the two drug groups. Half of the patients experienced nausea and vomiting, and one-fifth of the patients were reported to be sedated. Eight per cent of patients were reported to have experienced respiratory depression. Almost one-quarter of the patients experienced hypotension and pruritus. Compared with BF patients, EM patients were significantly more likely to experience respiratory depression (14.3\% compared with $3.8 \%$ ), hypotension (41.4\% compared with $13.9 \%$ ) and pruritus (35.7\% compared with $15.7 \%$ ). 


\section{DISCUSSION}

The data collection process for this audit was time consuming and, in some cases, incomplete (ie, coanalgesia information for 38 patients). Yet, the findings of the audit led to several changes in the management of acute pain postoperatively at the PRHC. It was also the impetus for the development of a formal APMS. The research by Ready et al (1) was used in developing the APMS. Ready et al identified several elements in a successful APMS service, including formal policies and procedures to be carried out by an APMS team consisting of an anesthesiologist and a clinical nurse specialist.

Before the establishment of the APMS at the PRHC, patients were followed postoperatively by the anesthesiologist who provided the anesthetic. With the establishment of a formal APMS, a team was developed that included an anesthesiologist and an APMS nurse clinician. The anesthesiologist rotated through the APMS on a weekly basis. On the weekend, the second-call anesthesiologist followed the APMS patients. The team performed rounds on all patients in the morning and then again in the afternoon because new patients were to be included in the service.

Before the establishment of the formal APMS, it was difficult to audit the effectiveness of the treatment of acute pain postoperatively because of the absence of a data collection system. As indicated previously, data for the audit had to be gleaned from several sources. With the implementation of the new data collection system, data were collected at each visit, the database was updated daily and the information was used to make treatment decisions about patients. The data management system began in the operating room, where the 'daily APMS flowsheet' was partially completed and placed in the progress notes of the chart. The flowsheet included salient features of the patient's medical history, including the operating room experience. In addition, while in the operating room, preprinted 'epidural order sheets' were also completed and placed on the chart. A detachable copy of the order sheet was removed and deposited in the Post Anesthetic Care Unit or the Labour and Delivery Ward envelope. The order sheets were picked up by the nurse clinician. In this way, patients were entered onto the APMS daily census. While in the Post Anesthetic Care Unit, the 'epidural nursing flowsheet' was initiated and eventually placed at the patient's bedside.

Before the formal service, charting during patient rounds (if rounds were performed) was inconsistent and, in some cases, nonexistent. With the introduction of the flowsheets, information from the rounds was recorded on the 'daily APMS flowsheet'. The information was also recorded on the nurse clinician's copy of the flowsheet, which was generated from the computerized database and was available at the beginning of rounds. At the end of rounds, the nurse clinician entered the information from the worksheet into the computerized database and printed a new worksheet. Monthly reports also were generated for both the nursing and anesthesiology departments, and were used for both administrative and quality improvement purposes. The census information for each patient included name, health card number, present mode of therapy (eg, patient-controlled analgesia, epidural), coanalgesia, tran-
TABLE 3

Percentage of patients with side effects and cross-tabulation by type of epidural medication

\begin{tabular}{ccccc}
\hline Characteristic & Total (\%) & $\begin{array}{c}\text { Bupivacaine/ } \\
\text { fentanyl (\%) }\end{array}$ & $\begin{array}{c}\text { Epidural } \\
\text { morphine (\%) }\end{array}$ & $\mathbf{P}$ \\
\hline $\begin{array}{c}\text { Nausea and/or } \\
\text { vomiting }\end{array}$ & $\mathrm{n}=178$ & $\mathrm{n}=108$ & $\mathrm{n}=70$ & \\
$\quad$ No & $89(50.0)$ & $51(47.2)$ & $38(54.3)$ & 0.357 \\
Yes & $89(50.0)$ & $57(52.8)$ & $32(45.7)$ & \\
Sedation & $\mathrm{n}=178$ & $\mathrm{n}=108$ & $\mathrm{n}=70$ & \\
No & $141(79.2)$ & $88(81.5)$ & $53(75.7)$ & 0.354 \\
Yes & $37(20.8)$ & $20(18.5)$ & $17(24.3)$ & \\
Respiratory & & & & \\
depression & $\mathrm{n}=176$ & $\mathrm{n}=106$ & $\mathrm{n}=70$ & \\
No & $162(92.0)$ & $102(96.2)$ & $60(85.7)$ & 0.012 \\
Yes & $14(8.0)$ & $4(3.8)$ & $10(14.3)$ & \\
Hypotension & $\mathrm{n}=178$ & $\mathrm{n}=108$ & $\mathrm{n}=70$ & \\
No & $134(75.3)$ & $93(86.1)$ & $41(58.6)$ & 0 \\
Yes & $44(24.7)$ & $15(13.9)$ & $29(41.4)$ & \\
Pruritis & $\mathrm{n}=178$ & $\mathrm{n}=108$ & $\mathrm{n}=70$ & \\
No & $136(76.4)$ & $91(84.3)$ & $45(64.3)$ & 0.002 \\
Yes & $42(23.6)$ & $17(15.7)$ & $25(35.7)$ & \\
\hline & & & & \\
\hline
\end{tabular}

sitional analgesia and side effects at each visit. The computerized database captured all of the information collected in the retrospective study, in addition to other variables thought to be of importance. Future plans include the implementation of a portable computer to be used on APMS rounds, so that information can be entered at the bedside.

The pain scores and the incidence of side effects were similar to those reported in the literature $(7,8)$. The adverse effects of epidural analgesics reported in the literature include nausea and vomiting, pruritus, urinary retention, ileus formation, respiratory depression, oversedation, hypotension, motor block and neurological complications (9-13). The dosages of EM and fentanyl, as well as the administration of EM as a bolus, would contribute to the relatively high prevalence of side effects. The conservative definition of respiratory depression (fewer than 10 breaths/min compared with fewer than eight breaths $/ \mathrm{min})(7,14)$ also contributed to the rate of respiratory depression. The audit also cited a significantly higher rate of respiratory depression, hypotension and pruritus in EM patients compared with BF patients. The literature supports the potential for EM boluses to contribute to hypotension $(14,15)$. In addition, therapies such as antiemetics to treat nausea and vomiting, and antihistamines to treat pruritus can result in hypotension and respiratory depression (16). Hence, the therapy initiated to treat side effects of EM may, in turn, have increased the incidence of other side effects. In addition, despite the relatively high doses of EM, BF patients were receiving superior pain control.

Several initiatives were established to address how EM was being administered in the treatment of acute pain. These included using a flush with EM administration, administering $\mathrm{EM}$ on a regular rather than on an as needed basis, making a 
prepackaged BF combination available, and placing the catheter closer to the incision site to increase the effectiveness and decrease the dosage required. Factors that may have contributed to BF success were also encouraged, such as the increased use of coanalgesia and transitional analgesia.

\section{CONCLUSIONS}

With the increasing demand for better pain control, a formalized approach to acute pain management has become a necessary part of providing safe and consistent care for postoperative and/or acute pain patients. Experience at the PRHC suggests that the APMS should have a committee overseeing the service.

This committee should include representation from the department of surgery, the nursing administration, the pharmacy, patient areas where the APMS would routinely follow patients (eg, the intensive care unit, surgical wards, pediatrics), and an anesthesiologist and a nurse clinician, both with formal training and/or experience in the management of acute pain. Ongoing data collection needs to be established to determine the effectiveness of the service, to identify any problems that may arise, and to provide information for the planning and implementation of future services. Other factors that were believed to contribute to the success of the APMS at the PRHC included standardized order sheets, data sheets, a computerized database, patient and provider education programs, coanalgesia and transitional analgesia as part of routine care, appropriate epidural catheter placement, a postoperative nausea and vomiting algorithm, and a treatment regimen for pruritus.

In summary, the results of a simple audit resulted in the establishment of a formal APMS and had an impact on physi-

\section{REFERENCES}

1. Ready LB, Edwards WT. Management of acute pain. Seattle: International Association for the Study of Pain, 1992:22-5.

2. Badner NH. Local anaesthetics in postoperative pain reliefwhat is their role? Can J Anaesth 1994;41:R42-7.

3. Singelyn FJ, Deyaert M, Joris D, Pendeville E, Gouverneur JM. Effects of intravenous patient-controlled analgesia with morphine, continuous epidural analgesia, and continous three-in-one block on postoperative pain and knee rehabilitation after unilateral total knee arthroplasty. Anesth Analg 1998;87:88-92.

4. Watt-Watson JH, Donovan MI. Pain Management: A Nursing Perspective. St Louis: Mosby, 1992:401-25.

5. Sandler AN, Katz J. Post-op analgesia and patient satisfaction. Can J Anaesth 1990;41:1-5.

6. Wall PD, Melzack R. Testing pain mechanisms in persons in pain. In: Wall PD, Melzack R, eds. Textbook of Pain. Edinburgh: Churchill Livingstone, 1984.

7. Leith S, Wheatley RG, Jackson I, Madej TH, Hunter D. Extradural infusion analgesia for postoperative pain relief. Br J Anaesth 1994;73:552-8.

8. Schultz AM, Werba A, Ulbing S, Gollmann G, Lehofer F. Perioperative thoracic epidural analgesia for thoracotomy. Eur J Anaesthesiol 1997;6:600-3. cian practice. Both nurses and physicians were able to identify with the data and could see the direct effect of their practice on pain scores and side effects. The authors believe that it was the ability to identify directly with the results of the audit that led to changes in physician practice. It is hypothesized that the process involved three main steps: first, the data from the audit and the subsequent database allowed clinicians close to the process to incorporate the findings into their practice and to present these findings at clinical rounds to the Department of Anesthesiology; second, the nurse clinician and the nurses at the bedside were able to monitor the effects of practice changes by one or two physicians on VAS scores and side effects, and, in turn, encouraged other physicians to consider these findings when treating acute pain postoperatively; and third, findings in the literature were used to support what had been discovered in the audit and the subsequent database, and were used in the development of a formal APMS.

The establishment of an APMS formalized the practice changes and enabled continuous assessment of the impact of practice on the management of acute pain. Further studies are needed to assess not only the best way to treat acute pain postoperatively, but also how to encourage the use of this information by physicians in both academic and nonacademic hospitals.

ACKNOWLEDGEMENTS: The authors gratefully acknowledge the support and assistance of the Acute Pain Management Committee, the Department of Anesthesiology and the nursing staff at the PRHC.

9. Halpern SH, Arellano R, Preston R, et al. Epidural morphine vs hydormorphine in post-caesarean section patients. Can J Anaesth 1996;43:595-8.

10. Dyer RA, Anderson BJ, Michell WL, Hall JM. Postoperative pain control with a continuous infusion of epidural sufentanil in the intensive care unit: A comparison with epidural morphine. Anesth Analg 1990;71:130-6.

11. Littrell RA. Epidural analgesia. Am J Hosp Pharm 1991;48:2460-74.

12. Lutz LJ, Lamer TJ. Management of postoperative pain: Review of current techniques and methods. Mayo Clin Proc 1990;65:584-96.

13. Chaney KA. Side effects of intrathecal and epidural opioids. Can J Anaesth 1995;42:891-902.

14. Benedetti C. Intraspinal analgesia: An historical overview. Acta Anaesthesiol Scand 1987;31(Suppl):17-24.

15. Shafer AL, Donnelly AJ. Management of postoperative pain by continuous epidural infusion of analgesics. Clin Pharm 1991;10:745-65.

16. Leathem AM, Cadario BJ, Yamamoto AG. Drug Information Reference, 3rd edn. Vancouver: The BC Drug and Poison Information Centre, 1993. 


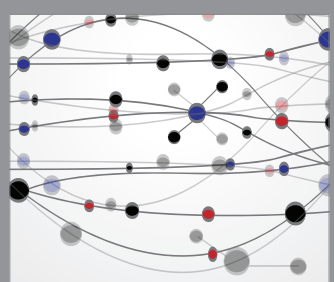

The Scientific World Journal
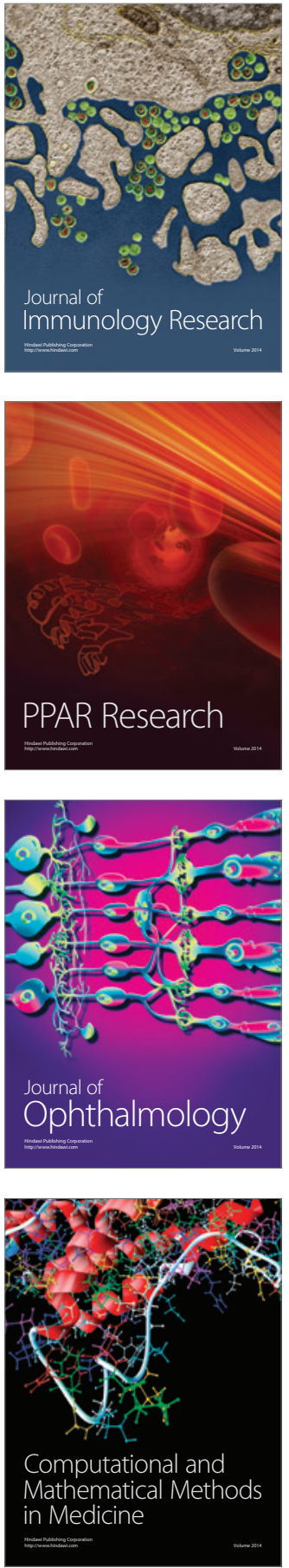

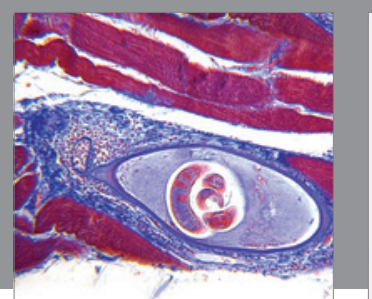

Gastroenterology Research and Practice

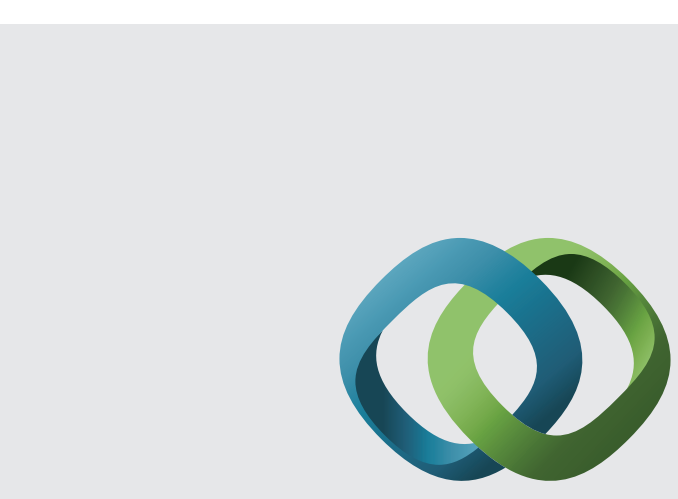

\section{Hindawi}

Submit your manuscripts at

http://www.hindawi.com
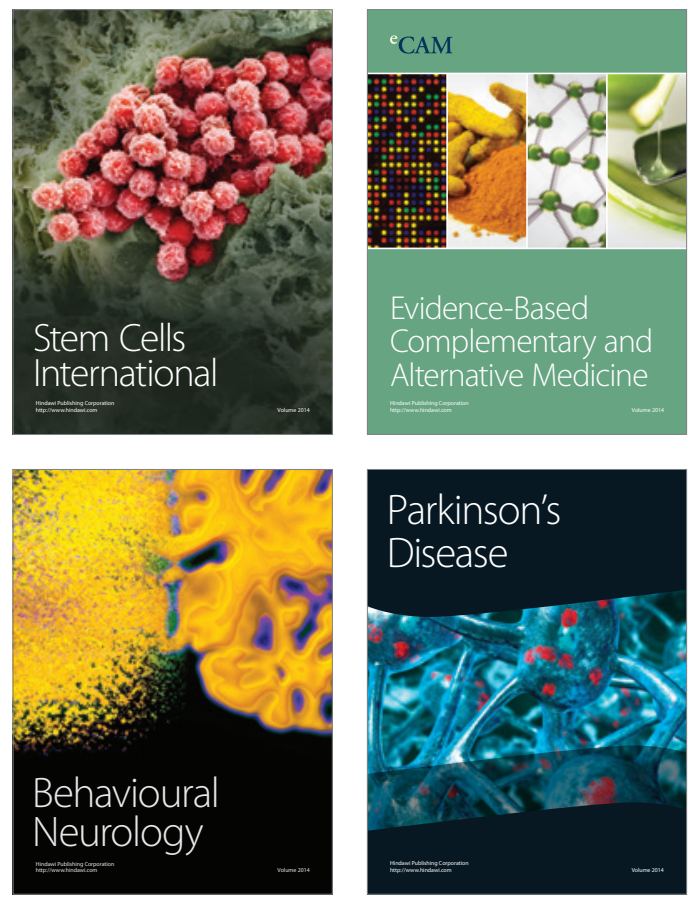
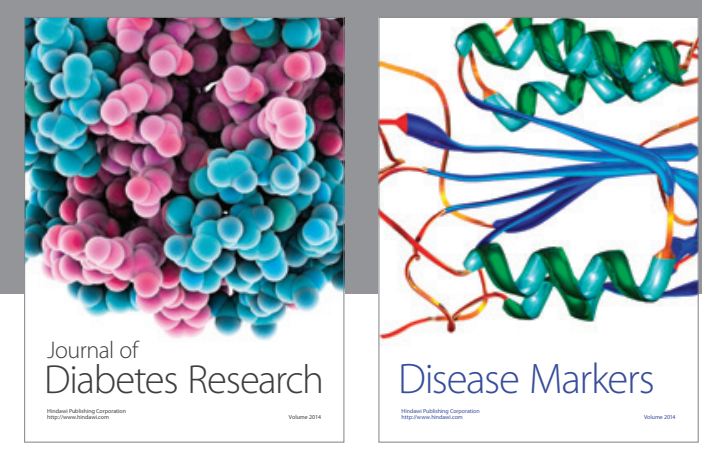

Disease Markers
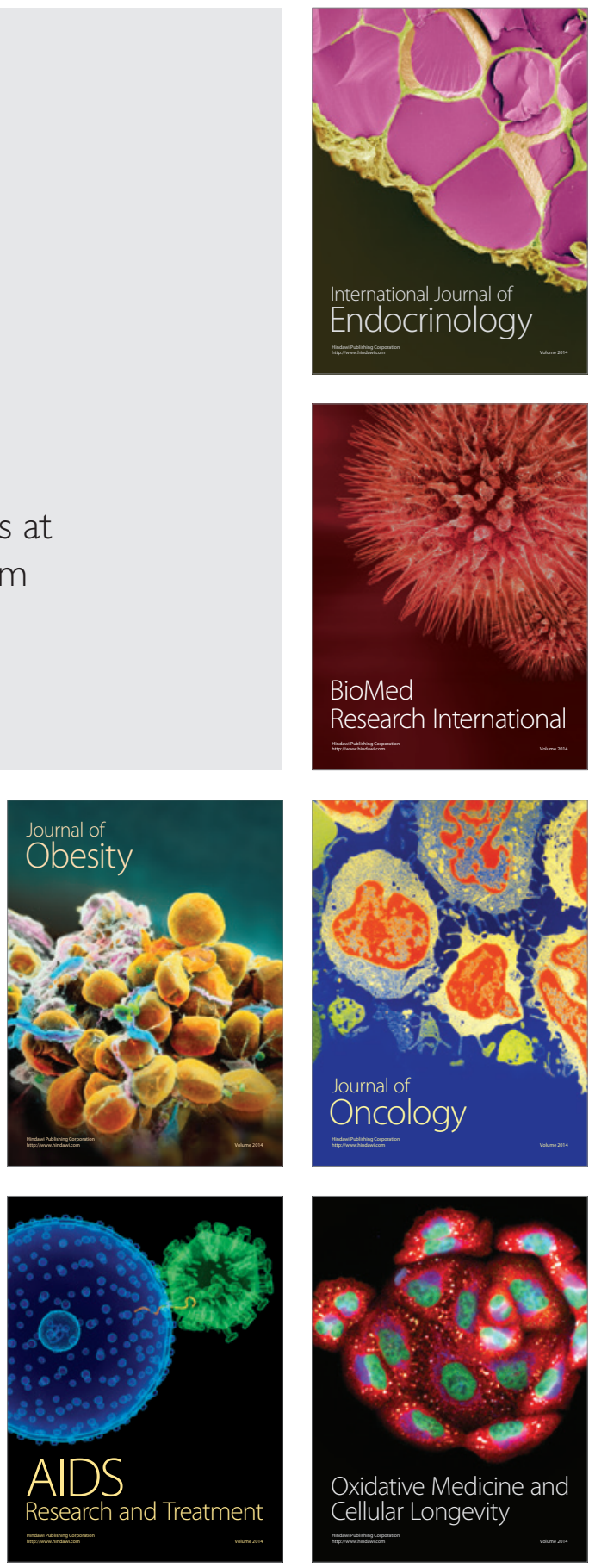